\title{
A broadband cavity ringdown spectrometer for in-situ measurements of atmospheric trace gases
}

\author{
M. Bitter ${ }^{1}$, S. M. Ball ${ }^{1, *}$, I. M. Povey ${ }^{1}$, and R. L. Jones ${ }^{1}$ \\ ${ }^{1}$ Centre for Atmospheric Science, Univ. Chemical Lab., Univ. of Cambridge, Lensfield Road, Cambridge, CB2 1EW, UK \\ *now at: Department of Chemistry, University of Leicester, University Road, Leicester, LE1 7RH, UK
}

Received: 12 April 2005 - Published in Atmos. Chem. Phys. Discuss.: 31 May 2005

Revised: 31 August 2005 - Accepted: 5 September 2005 - Published: 23 September 2005

\begin{abstract}
This paper describes a broadband cavity ringdown spectrometer and its deployment during the 2002 North Atlantic Marine Boundary Layer Experiment (NAMBLEX) to measure ambient concentrations of $\mathrm{NO}_{3}, \mathrm{~N}_{2} \mathrm{O}_{5}, \mathrm{I}_{2}$ and $\mathrm{OIO}$ at the Mace Head Atmospheric Research Station, Co. Galway, Ireland. The effective absorption path lengths accessible with the spectrometer generally exceeded $10 \mathrm{~km}$, enabling sensitive localised "point" measurements of atmospheric absorbers to be made adjacent to the other instruments monitoring chemically related species at the same site. For the majority of observations, the spectrometer was used in an open path configuration thereby avoiding surface losses of reactive species. A subset of observations targeted the $\mathrm{N}_{2} \mathrm{O}_{5}$ molecule by detecting the additional $\mathrm{NO}_{3}$ formed by the thermal dissociation of $\mathrm{N}_{2} \mathrm{O}_{5}$. In all cases the concentrations of the atmospheric absorbers were retrieved by fitting the differential structure in the broadband cavity ringdown spectra using a methodology adapted from long path differential optical absorption spectroscopy. The uncertainty of the retrieval depends crucially on the correct treatment and fitting of the absorption bands due to water vapour, a topic that is discussed in the context of analysing broadband cavity ringdown spectra. The quality of the measurements and the retrieval method are illustrated with representative spectra acquired during NAMBLEX in spectral regions around $660 \mathrm{~nm}\left(\mathrm{NO}_{3}\right.$ and $\left.\mathrm{N}_{2} \mathrm{O}_{5}\right)$ and $570 \mathrm{~nm}\left(\mathrm{I}_{2}\right.$ and OIO). Typical detection limits were 1 pptv for $\mathrm{NO}_{3}$ in an integration time of $100 \mathrm{~s}, 4 \mathrm{pptv}$ for OIO and $20 \mathrm{pptv}$ for $\mathrm{I}_{2}$ in an integration time of $10 \mathrm{~min}$. Additionally, the concentrations of atmospheric water vapour and the aerosol optical extinction were retrieved in both spectral regions. A companion paper in this issue presents the time series of the measurements and discusses their significance for understanding the variability of short lived nitrogen and iodine compounds in the marine boundary layer.
\end{abstract}

Correspondence to: S. M. Ball

(sb263@le.ac.uk)

\section{Introduction}

Cavity ringdown spectroscopy (CRDS) is now a wellestablished technique for studying weakly absorbing samples at wavelengths ranging from the ultraviolet to the far infrared regions of the electromagnetic spectrum (Wheeler et al., 1998; Berden et al., 2000). Numerous species of atmospheric importance have been detected by CRDS and related methods (Atkinson, 2003; Brown, 2003; Ball and Jones, 2003). For example, atomic $\mathrm{Hg}$ (Jongma et al., 1995), $\mathrm{CH}_{4}$ (Fawcett et al., 2002), $\mathrm{C}_{2} \mathrm{H}_{2}, \mathrm{CO}, \mathrm{CO}_{2}, \mathrm{NH}_{3}, \mathrm{H}_{2} \mathrm{O}$ (Baer et al., 2002), NO (Menzel et al., 2001) and aerosol particles (Smith and Atkinson, 2001) have all been quantified in ambient air. Usually these measurement have been achieved using light at a single wavelength or by scanning over a narrow absorption feature such as a single ro-vibrational line. However the electronic transitions of certain atmospheric species give rise to much broader absorption features, several or tens of nanometres in width. One such broadband absorber, $\mathrm{NO}_{3}$, has been detected in the atmosphere by cavity ringdown spectroscopy, as has the chemically related reservoir species, $\mathrm{N}_{2} \mathrm{O}_{5}$, via its thermal decomposition to $\mathrm{NO}_{3}$ (Brown et al., 2002b,a; Simpson, 2003). Again, the measurements were made with essentially monochromatic light at the peak of the molecule's $662 \mathrm{~nm}$ absorption band. The instrument of Brown et al. (2002a) achieved a detection limit of 0.5 pptv for $\mathrm{NO}_{3}$ and $\mathrm{N}_{2} \mathrm{O}_{5}$ for an integration time of $5 \mathrm{~s}$, whereas Simpson stated a projected sensitivity of $1.2 \mathrm{pptv}$ for $\mathrm{NO}_{3}$ or 1.6 pptv for $\mathrm{N}_{2} \mathrm{O}_{5}$ over a $25 \mathrm{~s}$ integration time.

The decay rate of a light pulse circulating inside a ringdown cavity depends on the reflection efficiency of the mirrors and the attenuation by gases and aerosol particles present between the mirrors. The atmosphere is a complex mixture of absorbing and scattering species whose overlapping absorptions can in principle all contribute to the optical losses within the cavity. These various losses must be separately quantified if measurements are to yield quantitative concentrations of the absorbers. One way this has been achieved

(C) 2005 Author(s). This work is licensed under a Creative Commons License. 


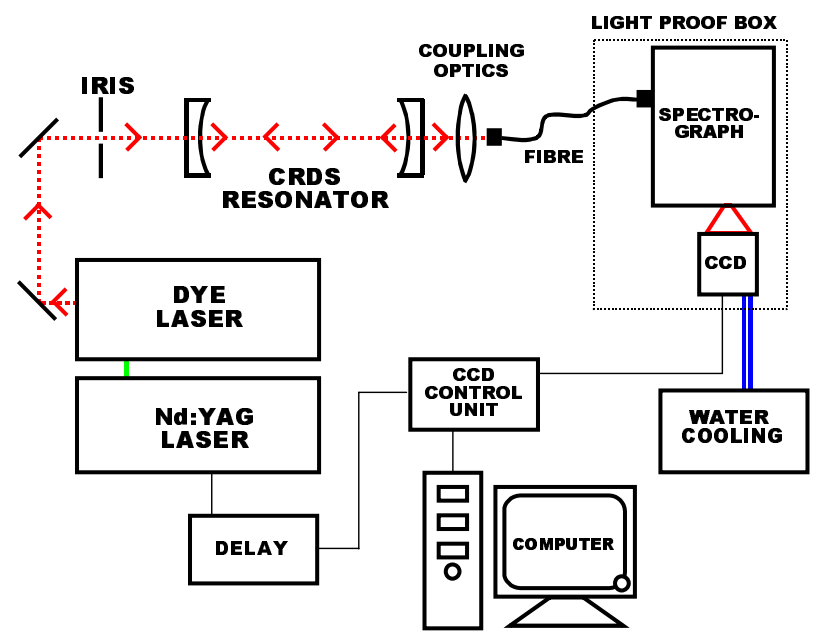

Fig. 1. A schematic diagram of the BBCRDS apparatus.

is to isolate the absorption due to a single target species by modulation of its concentration, for example by the selective removal of $\mathrm{NO}_{3}$ through its titration with $\mathrm{NO}$ (Brown et al., $2002 \mathrm{~b}$,a; Simpson, 2003). Variations in the ringdown time measured at a single wavelength can then be linked to variations in the concentration of the target absorber provided that its concentration is modulated more rapidly than variations in the other species contributing to the overall absorption. Another method is to separate the various contributions spectrally through the acquisition of an absorption spectrum over a range of wavelengths. The advantage of this approach is that the absorbers are identified unambiguously by fitting their unique spectral signatures to the differential structure in the measured absorption spectrum. This is the basis of long path differential optical absorption spectroscopy (DOAS) which has a long and successful history in the quantification of atmospheric absorbers, particularly those with spectrally broad absorption bands (Plane and Smith, 1995; Platt, 1999). The certainty with which the various absorbers can be quantified by DOAS depends crucially on obtaining absorption data over a wide wavelength range such that the broad, and often highly variable attenuation by atmospheric aerosol can be removed.

The broadband cavity ringdown spectrometer described here combines the sensitivity achievable in a compact ringdown cavity with the spectral discrimination of DOAS. Thus broadband cavity ringdown spectroscopy (BBCRDS) is analogous to a localised version of long path DOAS. Absorption spectra are obtained over the bandwidth of the light source, here a broadband dye laser, by detecting the cavity output simultaneously as function of time and wavelength. The following section describes the instrument and its deployment on the NAMBLEX campaign. Sections 3 and 4 describe the philosophy and the analysis methods used to retrieve the concentration of the various absorbers from BBCRDS spectra

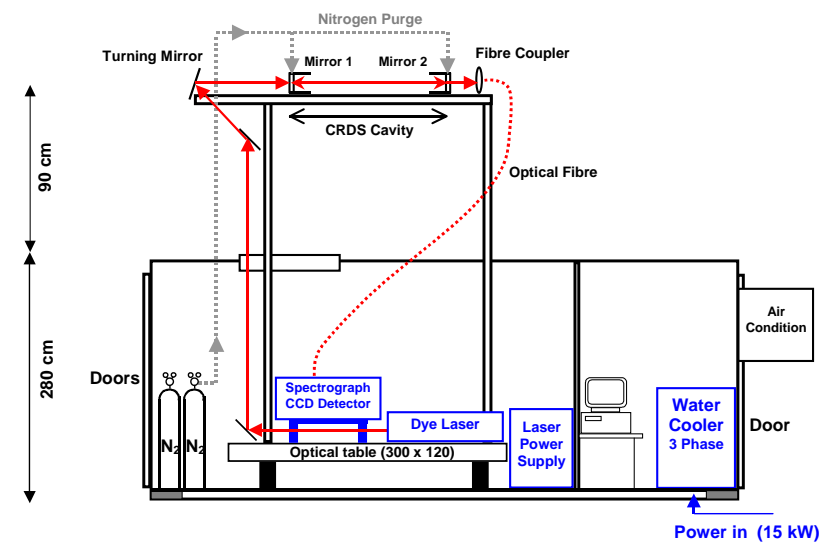

Fig. 2. The BBCRDS spectrometer in its cargo container during deployment on the NAMBLEX campaign.

acquired during the field work. Representative spectra are presented in Sect. 5 to illustrate the detection limits achievable with the instrument, and future directions are discussed in Sect. 6. Time series of the trace gas concentrations, water vapour amounts and aerosol extinctions measured during NAMBLEX are presented in a companion paper in this issue (Bitter et al., $2005^{1}$ ) in which their implications for the chemistry and structure of the marine boundary layer are also discussed.

\section{Experiment}

\subsection{General instrumentation}

The BBCRDS field instrument, a schematic diagram of which is shown in Fig. 1, is adapted from the apparatus used previously for laboratory studies of water vapour, $\mathrm{NO}_{3}$ and oxygen. The light source is broadband Nd:YAG pumped dye laser, and the simultaneous time- and wavelengthresolved detection of light leaking from the ringdown cavity is achieved using a clockable CCD camera mounted at the focal plane of a spectrograph. The instrument offers considerable flexibility because different wavelength regions can be accessed by exchanging the cavity mirrors and laser dyes, a routine procedure that can be accomplished in a few hours. Since many of the instrument's components have been discussed in detail elsewhere (Povey et al., 1998; Ball et al., 2001; Ball and Jones, 2003), the following sections concentrate primarily on its adaptation for field studies.

The instrument was housed in a cargo container as illustrated in Fig. 2. All of the optical components were mounted

\footnotetext{
${ }^{1}$ Bitter, M., Ball, S. M., Povey, I. M., Jones, R. L., Saiz-Lopez, A., and Plane, J. M. C.: Measurements of $\mathrm{NO}_{3}, \mathrm{~N}_{2} \mathrm{O}_{5}$, OIO, $\mathrm{I}_{2}$, water vapour and aerosol optical depth by broadband cavity ring down spectroscopy during the NAMBLEX campaign, Atmos. Chem. Phys. Discuss, in preparation, 2005.
} 


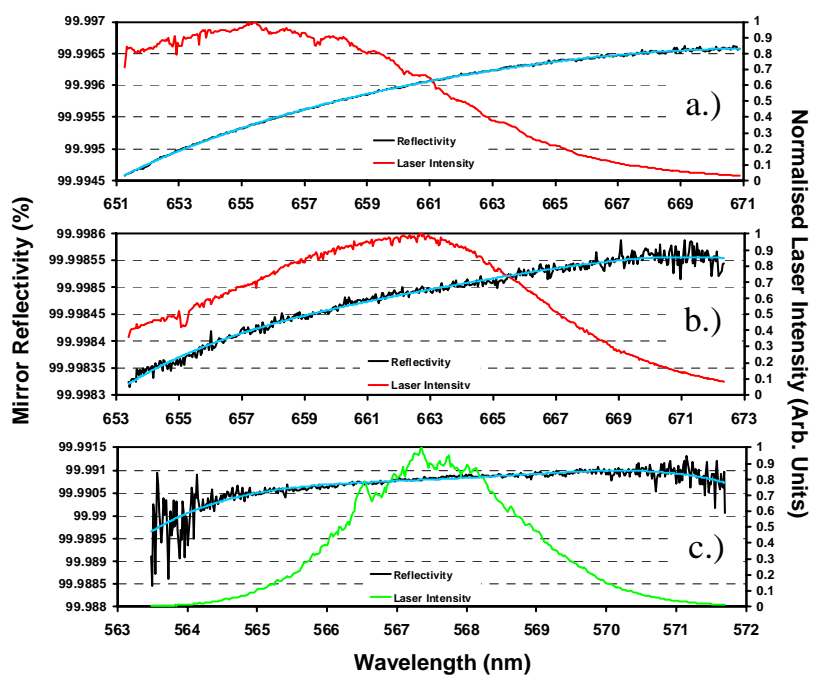

Fig. 3. Examples of the spectral distribution of the broadband dye laser output at wavelengths used to detect $\mathrm{NO}_{3}$ and $\mathrm{N}_{2} \mathrm{O}_{5}$ (red curves) or $\mathrm{OIO}$ and $\mathrm{I}_{2}$ (green curve). Panels (a) to (c) also show the wavelength dependent reflectivities of the three pairs of CRDS mirrors used during NAMBLEX (measured reflectivities in black and polynomial fits in blue; see also Table 1.)

on an optical table supported by pneumatic feet. Aluminium structural rails (Newport X95) bolted to the optical table supported the ringdown cavity outside the container, $90 \mathrm{~cm}$ above its roof and approx. $370 \mathrm{~cm}$ above ground level. A separate compartment within the container provided a small amount of office space for the operators and housed the control/data storage computer and a cooling unit (Thermal Engineering Systems, A4705, $4 \mathrm{~kW}$ ) recycling cooling water to the Nd:YAG laser. Dry nitrogen purge gas (BOC, purity: $99.998 \%$ ) was supplied to the ringdown cavity from gas cylinders stored in the container.

\subsection{The broadband light source}

A transversally pumped, twin-stage-amplifier dye laser (Spectron SL4000B) was employed as the broadband light source. The dye laser was pumped by a Q-switched Nd:YAG laser (Spectron SL803-G) at a $20 \mathrm{~Hz}$ repetition rate. The dispersion grating was removed from the dye laser cavity which allowed the entire broadband light output of the oscillator stage to be amplified. The broadband laser pulses were directed into the CRDS cavity after collimation with a pin hole iris.

The laser output was optimized for wavelength regions where the atmospheric target molecules absorb most strongly and possess unambiguous spectral signatures. Thus the $\mathrm{NO}_{3}$ radical was detected via the non-dissociative $\widetilde{B}^{2} \mathrm{E}^{\prime} \leftarrow \widetilde{X}^{2} \mathrm{~A}_{2}^{\prime}$ electronic transition peaking at $662 \mathrm{~nm}$ (Wayne et al., 1991). Broadband radiation centred at around $660 \mathrm{~nm}$ with a bandwidth of approximately $15 \mathrm{~nm}$ FWHM was generated by
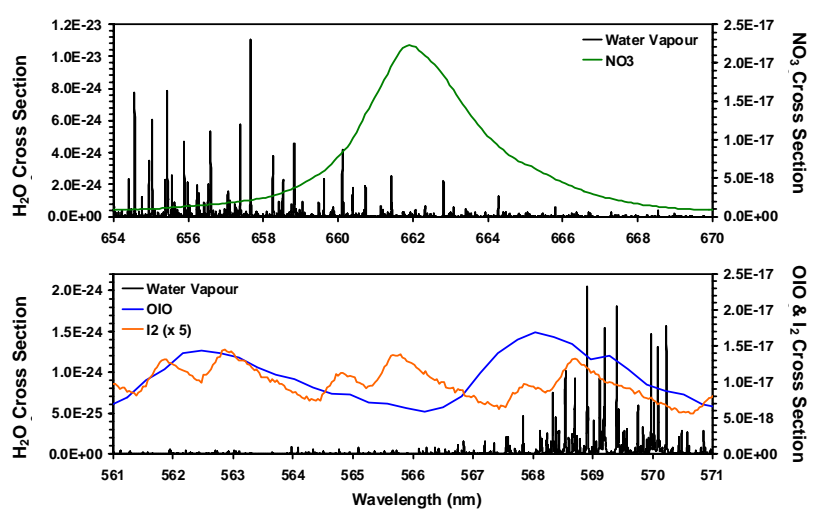

Fig. 4. The absorption cross sections of $\mathrm{NO}_{3}$ at $298 \mathrm{~K}$ (Yokelson et al., 1994) (green curve in top panel), OIO (Ashworth et al., 2002) and $\mathrm{I}_{2}$ (Saiz-Lopez et al., 2004) (blue and red data in bottom panel). Units are in $\mathrm{cm}^{2}$ molecule ${ }^{-1}$, and the $\mathrm{I}_{2}$ cross sections have been scaled by a factor of five. High resolution water absorption cross sections (black) are also shown in both spectral regions.

the dye laser operating with mixtures of DCM and LDS698 dyes dissolved in methanol/dimethyl sulfoxide. $\mathrm{I}_{2}$ and $\mathrm{OIO}$ were detected using their overlapping $\mathrm{B}^{3} \Pi\left(0_{u}^{+}\right) \leftarrow \mathrm{X}^{1} \Sigma_{g}^{+}$and $\widetilde{A}^{2} \mathrm{~B}_{2} \leftarrow \widetilde{X}^{2} \mathrm{~B}_{1}$ electronic transitions. Although the most strongly absorbing vibrational band of OIO's visible absorption spectrum is the $(5,1,0) \leftarrow(0,0,0)$ band at $548 \mathrm{~nm}$ (Himmelmann et al., 1996), the $(4,1,0) \leftarrow(0,0,0)$ band at $568 \mathrm{~nm}$ has a slightly larger differential absorption cross section and was selected for this work. The requisite radiation was obtained from the dye laser using a solution of Rhodamine $6 \mathrm{G}$ in methanol and water. However, the bandwidth of the laser output around $568 \mathrm{~nm}$ was significantly narrower $(4 \mathrm{~nm}$ FWHM) than that around $660 \mathrm{~nm}$, the reduced spectral coverage having a detrimental impact on the spectrometer's detection limits for $\mathrm{I}_{2}$ and OIO (see also Sect. 6). The typical spectral distribution of the laser output in both wavelength regions is illustrated in Fig. 3 and may be compared with the absorption cross sections of $\mathrm{NO}_{3}$ (Yokelson et al., 1994), OIO (Ashworth et al., 2002) and $\mathrm{I}_{2}$, (Saiz-Lopez et al., 2004) shown in Fig. 4.

\subsection{The ringdown cavity}

The ringdown cavity was formed by two highly reflective, plano-concave mirrors separated by $240 \mathrm{~cm}$. The mirrors were housed in custom-made mounts that were purged with dry filtered nitrogen to prevent contamination of the optical surfaces by the condensation of water vapour or by impaction of aerosol particles. The purge flow, $500 \mathrm{sccm}$ (standard cubic centimetres per minute), was regulated with a temperature stabilized mass flow controller (MKS Mass-Flo, $\mathrm{N}_{2}$, 1 standard litre per min). The mounts incorporated flexible steel bellows, spring mounted steel runners and three fine adjustment screws to permit alignment of the mirrors. Figure 5 


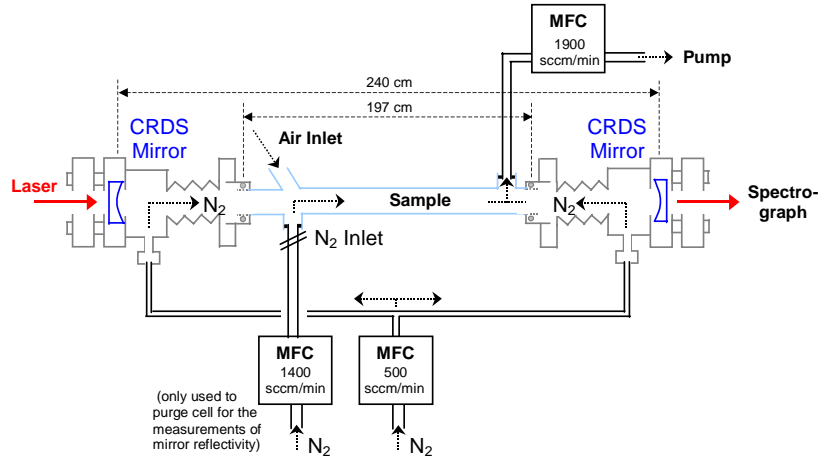

Fig. 5. The ringdown cavity and associated gas flows in the configuration used to detect $\mathrm{NO}_{3}+\mathrm{N}_{2} \mathrm{O}_{5}$. The heated glass tube between the mirror mounts could be flushed with dry nitrogen to record the ringdown times of the empty cavity, or be removed to allow measurements of $\mathrm{NO}_{3}$, OIO and $\mathrm{I}_{2}$ in an open path configuration (MFC = mass flow controller).

Table 1. Specifications of the CRDS mirrors used during the NAMBLEX field campaign. The typical path lengths were calculated from representative ringdown times achieved in ambient air at wavelengths away from the water bands. The path lengths therefore include the effects of aerosol extinction and Rayleigh scattering by air, whereas these effects have been removed from the mirror reflectivities given here and shown in Fig. 3.

\begin{tabular}{lccc}
\hline Mirror Pair & $\begin{array}{c}1 \\
\text { (Fig. 3a) }\end{array}$ & $\begin{array}{c}2 \\
\text { (Fig. 3b) }\end{array}$ & $\begin{array}{c}3 \\
\text { (Fig. 3c) }\end{array}$ \\
\hline Target Species: & $\mathrm{NO}_{3} / \mathrm{N}_{2} \mathrm{O}_{5}$ & $\mathrm{NO}_{3} / \mathrm{N}_{2} \mathrm{O}_{5}$ & $\mathrm{I}_{2} / \mathrm{OIO}$ \\
Centre $\lambda(\mathrm{nm}):$ & $670 \mathrm{~nm}$ & $670 \mathrm{~nm}$ & $570 \mathrm{~nm}$ \\
Peak Reflectivity (\%): & 99.9965 & 99.9985 & 99.991 \\
Typical atmospheric & & & \\
path length $(\mathrm{km}):$ & 20 & 24 & 13 \\
\hline
\end{tabular}

shows a schematic diagram of the ringdown cavity, the mirror mounts and the associated gas flows.

The cavity mirrors were, like the laser output, chosen for wavelengths where the atmospheric target species absorbed most strongly. The mean reflectivities of the various pairs of mirrors used during NAMBLEX are shown overlaid on spectral distributions of the laser output in Fig. 3. The reflectivities were calculated from ringdown times measured when the cavity was flushed with dry, micro-filtered nitrogen, and include the subtraction of Rayleigh scattering at $1 \mathrm{~atm}$ pressure (Nicolet, 1984). Table 1 summarises the specifications of the mirrors, all of which were supplied by Los Gatos Research Inc and had a diameter of $20 \mathrm{~mm}$ and a radius of curvature of $6 \mathrm{~m}$.

The cavity was configured in two different arrangements depending on the target molecule.

1.) Measurements of $\mathrm{NO}_{3}$ around $660 \mathrm{~nm}$ or of $\mathrm{OIO}$ and $\mathrm{I}_{2}$ around $570 \mathrm{~nm}$ were performed with an "open path" con- figuration in which ambient air occupied the central $197 \mathrm{~cm}$ section of the ringdown cavity between the open ends of the mirror mounts. The advantage of this arrangement was that the gases and ambient aerosol did not contact any surfaces on which they might be lost. But because the remaining length of cavity inside the mirror mounts was purged with non-absorbing dry nitrogen, it was necessary to correct the concentrations of the absorbers and aerosol extinction retrieved from fitting the BBCRDS spectra. The mirror mounts were assumed to be completely filled with dry nitrogen, and thus the retrieved concentrations were multiplied by a factor of $240 / 197=1.22$. It was also necessary to include the correction factor in the calculation of the water absorption cross sections prior to fitting the BBCRDS spectra (see Calculation of the linearized species cross sections in Sect. 4.3). The justification for applying this correction factor comes from the retrieval of water vapour amounts that agree closely with those measured by a commercial humidity sensor during the NAMBLEX campaign (see the companion paper).

The measurement of absolute absorber concentrations by CRDS requires that the ringdown times of the cavity containing the sample be compared with those of the empty cavity. In the present arrangement, ringdown times of the empty cavity were acquired by inserting a glass tube between the mirror mounts and purging the cavity with an additional $1400 \mathrm{sccm}$ of dry filtered nitrogen as shown in Fig. 5 .

2.) Measurements of the sum of $\mathrm{NO}_{3}$ and $\mathrm{N}_{2} \mathrm{O}_{5}$ (hereafter referred to as $\mathrm{NO}_{3}+\mathrm{N}_{2} \mathrm{O}_{5}$ ) were carried out in a closed system. A diaphram pump on the cavity's exhaust was used to draw ambient air through a glass tube (inner diameter $=1.45 \mathrm{~cm}$ ) inserted in between the mirror mounts. The net flow through the pump $(1900 \mathrm{sccm})$ was controlled with a mass flow controller (MKS Mass-Flo, $\mathrm{N}_{2}, 2$ standard litres per minute) and was composed of the $500 \mathrm{sccm}$ of dry nitrogen purging the mirror mounts plus $1400 \mathrm{sccm}$ of ambient air, see Fig. 5. Thus, the concentrations of $\mathrm{NO}_{3}+\mathrm{N}_{2} \mathrm{O}_{5}$, water vapour and the aerosol extinction deduced from fitting the BBCRDS spectra were multiplied by a factor of $1900 / 1400=1.36$ to correct for dilution of the sample flow by the mirror purge. Again this correction is confirmed by the retrieval of the right amounts of water vapour. To reduce losses of $\mathrm{NO}_{3}$ and $\mathrm{N}_{2} \mathrm{O}_{5}$ to the cell walls, its internal surfaces were coated with halocarbon wax (Halocarbon Inc., Series 600). The glass tube was also heated to promote the thermal decomposition of $\mathrm{N}_{2} \mathrm{O}_{5}$ to $\mathrm{NO}_{3}$. The temperature of the tube was regulated by a PID controller (PID = ProportionalIntegral-Derivative) interfaced to one of several PT100 platinum resistance thermometers and a heating band wrapped around the outside of the glass cell.

The thermal decomposition of $\mathrm{N}_{2} \mathrm{O}_{5}$ and the ringdown decay proceeded simultaneously in the cavity. The equilibrium constant for Reaction 1 is a strong function of temperature.

$\mathrm{NO}_{3}+\mathrm{NO}_{2}+(\mathrm{M}) \leftrightarrow \mathrm{N}_{2} \mathrm{O}_{5}+(\mathrm{M})$ 
$\ln \left(\mathrm{K}_{e q}\right)=-60.46+10724 / \mathrm{T}$, (Wängberg et al., 1997)

A numerical simulation considered the rates of the forward and back reactions of $\mathrm{R} 1$ at the high pressure limit with nitrogen gas as third body. For the usual residence time of $9.0 \mathrm{~s}$ within the ringdown cavity, the simulation calculated that $68 \%$ of the total number of $\mathrm{N}_{2} \mathrm{O}_{5}$ molecules present within the ringdown cavity had been decomposed to $\mathrm{NO}_{3}$ at $40^{\circ} \mathrm{C}$, with $88 \%$ decomposition at $50^{\circ} \mathrm{C}$ and $95 \%$ decomposition at $60^{\circ} \mathrm{C}$. For the NAMBLEX measurements, the cavity was typically heated to $60^{\circ} \mathrm{C}$.

A series of laboratory experiments were performed to estimate the amount of $\mathrm{NO}_{3}$ lost to the surfaces of the heated glass tube at $60^{\circ} \mathrm{C}$. A dilute flow of $\mathrm{N}_{2} \mathrm{O}_{5}$ in dry nitrogen $(270 \mathrm{sccm})$ was preheated to form $\mathrm{NO}_{3}$ and then introduced into the heated glass tube through a sliding injector. The majority of the flow through the glass tube was made up of a separate stream of dry or humidified nitrogen $(1900 \mathrm{sccm})$ flowing past the sliding injector. The total flow was exhausted through a T-piece into a short ringdown cavity where the concentration of $\mathrm{NO}_{3}$ remaining in the flow was quantified by BBCRDS as a function of the residence time in the heated glass tube. A first order rate constant for the loss of $\mathrm{NO}_{3}$ on the halocarbon wax coating was found to be $\mathrm{k}=0.036( \pm 0.011) \mathrm{s}^{-1}$, and no significant dependence of the loss rate on humidity was observed. Given the rate of wall loss and the sample's residence time inside the glass tube during the NAMBLEX measurements, the retrieved $\mathrm{NO}_{3}+\mathrm{N}_{2} \mathrm{O}_{5}$ amounts needed to be increased by a factor of $1.38( \pm 0.14)$ to account for the loss of $\mathrm{NO}_{3}$ on the walls of the ringdown cavity.

The net effect of the corrections for dilution, incomplete thermal decomposition of $\mathrm{N}_{2} \mathrm{O}_{5}$ and wall losses of $\mathrm{NO}_{3}$ required that the $\mathrm{NO}_{3}+\mathrm{N}_{2} \mathrm{O}_{5}$ amount retrieved from the DOAS fitting be multiplied by $1.97 \pm 0.61$. The major uncertainty in this net correction factor is attributable to the $\mathrm{NO}_{3}$ wall losses, the first order rate coefficient for which was only measured to within $\pm 30 \%$.

\subsection{Light detection}

Broadband radiation exiting the ringdown cavity was collected by a microscope lens ( 0.10 numerical aperture) and focused into a $200 \mu \mathrm{m}$ diameter optical fibre. The cavity ouput was conveyed by the fibre to an imaging spectrograph for wavelength dispersion. The spectrograph was a CzernyTurner type instrument (Chromex 250 IS) with f/4 receiving optics, a slit width of $50 \mu \mathrm{m}$ and a focal length of $250 \mathrm{~mm}$. Two of the spectrometer's turret-mounted diffraction gratings were employed in the measurements: (i) a holographic grating with 2400 grooves $/ \mathrm{mm}$ giving a spectral coverage of $7.3 \mathrm{~nm}$ around $660 \mathrm{~nm}$ or $8.2 \mathrm{~nm}$ around $570 \mathrm{~nm}$, (ii) a ruled grating with 1200 grooves $/ \mathrm{mm}$ giving a coverage of $18.6 \mathrm{~nm}$ at $660 \mathrm{~nm}$ (this grating was not used in the present measurements of the iodine compounds due to the limited

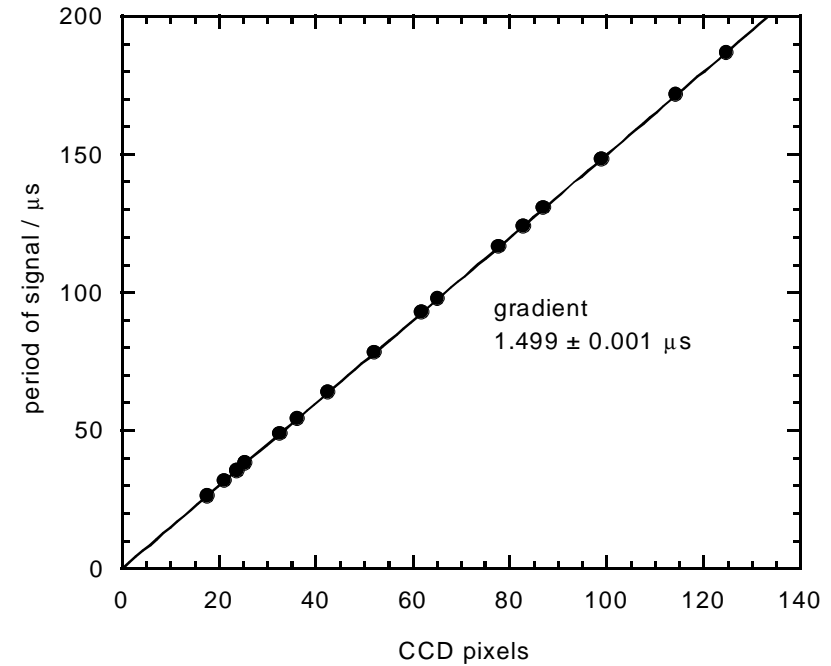

Fig. 6. Determination of the CCD clocking rate using modulated output from a light emitting diode. The clocking rate of $1.499 \pm 0.001 \mu$ s per pixel is given by the gradient of the linear fit.

bandwidth of the laser output around $570 \mathrm{~nm}$ ). The spectral resolution of BBCRDS spectra depended largely on the resolution achievable by the spectrograph which was ca 0.1 and $0.2 \mathrm{~nm} \mathrm{FWHM}$ at $660 \mathrm{~nm}$ for the 2400 grooves $/ \mathrm{mm}$ and 1200 grooves/mm gratings respectively.

The wavelength-dispersed radiation was imaged onto a CCD camera mounted at the focal plane of the spectrograph. The spectrograph and its camera were housed in a light proof metal box. The camera (Astromed 4201 DDE controller and TE3/A head) contained an EEV 37-10 chip with an image sector of 512 pixels along the wavelength dispersed axis and 512 pixels along the frame transfer axis. The chip also contained a storage section of a further $512 \times 512$ pixels into which data integrated in the image section was transferred prior to readout. The individual pixel size was $15 \mu \mathrm{m} \times 15 \mu \mathrm{m}$.

The CCD camera's operation in BBCRDS measurements has been discussed in some detail by (Ball and Jones, 2003). Briefly, the image section of the chip was protected by a mylar mask such that only ten rows of pixels were illuminated. The spectrally resolved cavity output was recorded as a function of time using a fast phased sequence of "clocking" voltages to move photo-charges generated in the exposed rows of the CCD to behind the mylar mask. The clocking sequence was initiated by a delayed trigger synchronised to the discharge of the Nd:YAG laser's flashlamps. Images due to summation of up to 255 ringdown events could be recorded on-chip by reverse-clocking the stored charges and repeating the clocking procedure. After a defined number of recordings had been summed on-chip, the charges were read out and stored in binary format on the control PC. A typical sequence of measurements consisted of acquiring batches of 


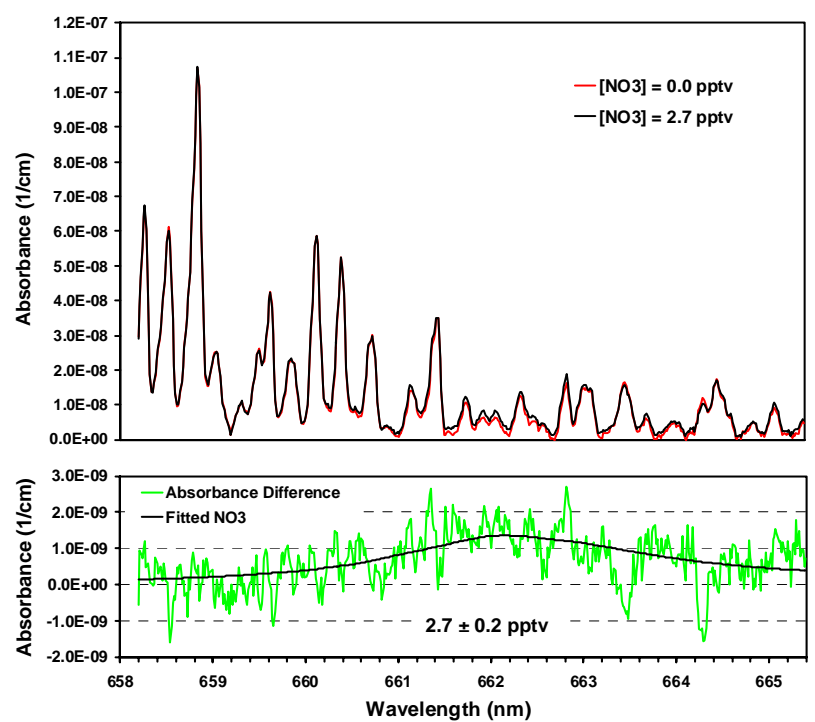

Fig. 7. (Top panel) BBCRDS absorbance spectra around $660 \mathrm{~nm}$ from the NAMBLEX field campaign (after subtraction of the aerosol continuum). The mixing ratios of ambient $\mathrm{NO}_{3}$ are zero (red) and $2.7 \mathrm{pptv}$ (black). The spectra derive from the average of the ringdown times fitted to $190 \mathrm{CCD}$ images, each the on-chip integration of 100 ringdown events with a total acquisition time of 42 minutes. (Bottom panel) The absorption due to $\mathrm{NO}_{3}$ is apparent from the difference in the two spectra above, overlaid here by the fitted $\mathrm{NO}_{3}$ absorption cross sections.

$20 \mathrm{CCD}$ images (each the summation of e.g. 100 ringdown events) for the cavity purged with $\mathrm{N}_{2}$, followed by a long run of similar acquisitions with ambient air. Measurements with the purged cavity were repeated at regular intervals to check for degradation of the mirror reflectivity.

The fastest clocking rate of the present system is $0.5 \mu \mathrm{s}$ per pixel row which, after convolution over the ten pixel rows exposed by the mask, yields a time resolution of $5 \mu \mathrm{s}$. Ringdown times for ambient samples during NAMBLEX depended primarily on the amount of aerosol extinction, but were typically around $50 \mu \mathrm{s}$. Thus slower clocking rates of $1.0,1.5,2.0$ and $3.0 \mu$ s per row were used to disperse the decaying signals over the full extent of the CCD's image section (for example see the decay traces in Fig. 8 of Sect. 3).

The clocking rates were measured independently in the laboratory by illuminating the CCD with broadband radiation from a light emitting diode (LED). The LED's intensity was modulated with a regular sequence of square pulses from a pulse generator (Thurlby Thandar TGP110). Figure 6 shows a plot of the average number of pixels between light pulses in the CCD images versus the period of the signal from the pulse generator. The measured clocking rate of $1.499 \pm 0.001 \mu \mathrm{s}$ is in excellent agreement with the $1.5 \mu \mathrm{s}$ clocking rate specified in the CCD acquisition software, and other clocking rates showed a similarly close agreement.
Dark current and electronic read out noise contributed around 5 counts per pixel. To reduce the effects of varying dark current and of stray light, dark current images were recorded with the same clocking sequences but with the laser beam blocked. The average of 10 to 20 such dark current images was subtracted from each CCD image on a pixel-bypixel basis before further processing. Attempts were also made to reduce the significance of systematic errors. The charge transfer efficiencies of a few individual CCD pixels seemed to have been reduced, leading to isolated spikes on ring down traces. Furthermore, a number of ringdown images were compromised by failure of the clocking sequence to initiate properly. The analysis software, as described later, included two filters to exclude such faulty traces.

\section{Broadband cavity ringdown decays and the retrieval of multiple absorbers}

Water vapour is by far the largest contributor to the differential structure in the BBCRDS spectra of ambient samples. It is therefore crucial that the analysis procedure treats water vapour's spectroscopy quantitatively when attempting to fit the much weaker underlying absorption features due to $\mathrm{NO}_{3}$ or other trace gases. Slight errors in fitting the water absorption features have been shown to mask the $\mathrm{NO}_{3}$ absorption features and lead to spurious $\mathrm{NO}_{3}$ signals (Bitter, 2004). Figure 7 illustrates the relative magnitudes of the water vapour and $\mathrm{NO}_{3}$ absorptions in BBCRDS spectra of ambient samples. The spectra were recorded during the NAMBLEX campaign around midnight between the 2nd and 3rd August 2002 in a period when the $\mathrm{NO}_{3}$ amounts measured by BBCRDS were either zero (red spectrum) or small (black spectrum) - see the time series in the companion paper (Bitter et al., $2005^{1}$ ). A sloping (linear) offset has been subtracted from each spectrum to remove the aerosol extinction, and the black spectrum has been scaled by a factor of 1.03 to correct for a slight decrease in the water vapour concentration between the observations. The spectra are the average of 190 CCD images each the on-chip summation of 100 rigdown events. The total acquisition time of each spectrum, $42 \mathrm{~min}$, is therefore much longer than that typically employed in the BBCRDS measurements (100 s), but serves here to minimise the measurement noise. The lower panel of Fig. 7 shows the difference in the two BBCRDS spectra above. A numerical fit of the cross section (Yokelson et al., 1994) to the small but obvious $\mathrm{NO}_{3}$ signal yields a concentration of $2.7 \pm 0.2 \mathrm{pptv}$ in good agreement with the difference between the average $\mathrm{NO}_{3}$ amounts retrieved from fitting the individual spectra.

The absorbance spectra shown above in Fig. 7 were calculated from one of the standard equations of cavity ringdown spectroscopy equation (Wheeler et al., 1998; Berden et al., 
2000):

$\alpha\left(\lambda_{j}\right)=\sum_{i} \sigma_{i}\left(\lambda_{j}\right) \cdot n_{i}=\frac{1}{c} \cdot\left[\frac{1}{\tau\left(\lambda_{j}\right)}-\frac{1}{\tau_{0}\left(\lambda_{j}\right)}\right]$

where in this work $\tau\left(\lambda_{j}\right)$ is the ringdown time of the cavity containing the ambient sample and $\tau_{0}\left(\lambda_{j}\right)$ is the ringdown time of the cavity when flushed with dry filtered nitrogen. The wavelengths $\lambda_{j}$ refer to the centre wavelength of the light falling onto the various pixels $(j=1,2, \ldots .512)$ along the wavelength dispersed axis of the CCD camera. The summation is conducted over all species $i$ that absorb (or scatter) within the spectral range of the measurement. Absolute concentrations of the molecular absorbers (either water vapour and $\mathrm{NO}_{3}$ or water vapour, OIO and $\mathrm{I}_{2}$ depending on the wavelength region) were retrieved by simultaneously fitting the absorption spectrum $\alpha\left(\lambda_{j}\right)$ with absorption cross sections of the molecular absorbers. The retrieval problem is thus overdetermined because the concentration of a small number of species plus a linear or quadratic offset to account for the aerosol extinction is retrieved from a set of, in this case, 512 wavelength resolved measurements. The analysis procedure is further outlined in Sect. 4. However, first it is necessary to discuss the treatment of water vapour's narrow absorption features in broadband ringdown measurements.

Figure 8 shows examples of ringdown traces acquired with the BBCRDS instrument. Although these data come from laboratory experiments rather than field observations, they nevertheless serve to illustrate key points concerning the acquisition and treatment of CCD images including issues associated with the spectroscopy of water vapour which must be addressed quantitatively. The data in Fig. 8 were extracted from a single column of the CCD image for pixels sampling light at $\lambda=661.5 \mathrm{~nm}$ resonant with a strong water absorption line (see for example Fig. 7). The blue trace with the longer decay time was acquired when flushing the cavity with dry nitrogen whereas the more rapidly decaying grey trace was for a sample of humidified nitrogen at $\mathrm{RH}=95.7 \%$.

The CCD clocking sequence begins somewhat before the arrival of the laser pulse. In the case of the traces in Fig. 8, the laser is triggered on the tenth step of the clocking sequence. The dark portions at the start and the end of the ringdown traces serve to confirm that the dark current has been correctly subtracted from the CCD images. The finite width of the mask (10 pixel rows) means that each row in the CCD image is the integration of photons leaking from the cavity during the previous ten clocking steps. Thus the intensity builds to a maximum over the ten clocking steps following the laser pulse as (dark current) photo-charges accumulated before the laser had fired are clocked through the exposed rows of the CCD chip. It is worth noting that the pixel row with the maximum number of counts therefore already contains the signature of the molecular absorbers from the integration of photons held inside the cavity for up to ten clocking steps. Following the maximum, the number of counts decays along
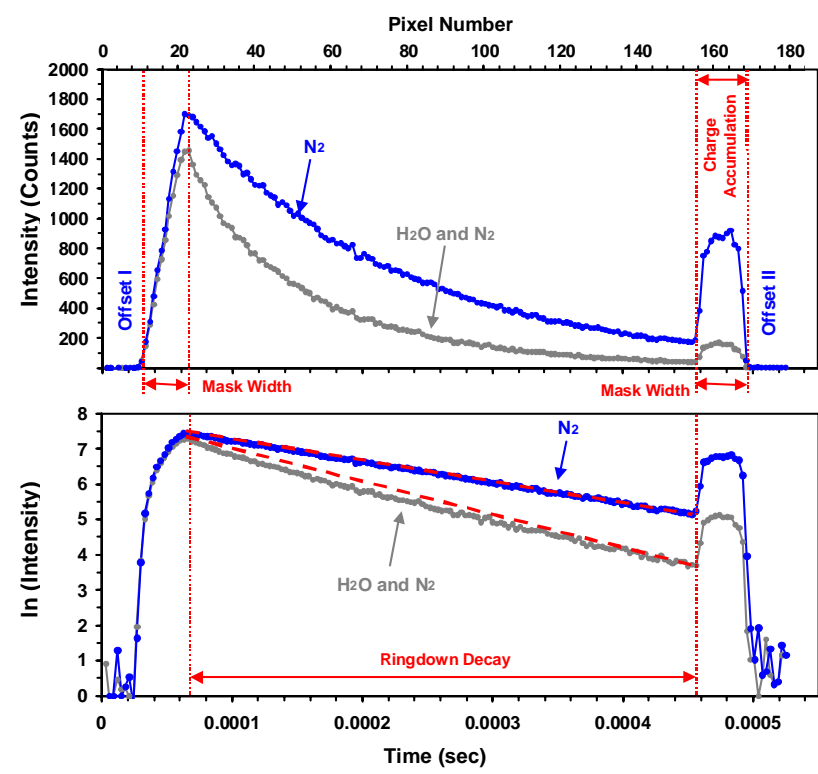

Fig. 8. (Top panel) Examples of ringdown decays in humidified (grey) and dry (blue) nitrogen. The data were extracted from a single column of the CCD images at $\lambda=661.5 \mathrm{~nm}$ on resonance with a strong water absorption line. The laser pulse is injected into the cavity on the tenth step of the clocking sequence, and the finite width of the mask on the front of the CCD chip results in the ringdown decays being convolved over 10 rows of pixels. After 150 steps, the clocking sequence waits in charge accumulation region for approx 1 $\mathrm{ms}$ to integrate signal from the tail of the ringdown decay. (Bottom panel) Natural logarithm of the intensity versus time illustrating the linear fits (dashed red lines) used to determine the ringdown times of the flushed cavity, $\tau_{0}(\lambda)$ in blue, and the sample, $\tau(\lambda)$ in grey. Note the multi-exponential behaviour of the sample's ringdown decay.

with the decaying intensity of light leaking from the ringdown cavity. After 150 steps, the clocking sequence pauses for approx. $1 \mathrm{~ms}$ to integrate the remainder of the photons from the tail of the ringdown decay, shown as the accumulation region in Fig. 8. The clocking sequence is then reversed to reset the camera to capture the next ringdown event. The accumulation region of the image proved particularly useful when optimising the cavity alignment because signals in this part of the CCD image arise from photons that have been circulating inside the cavity for long periods. Hence this region shows the largest differential structure due to the molecular absorbers, and the number of counts is a sensitive indicator of the ringdown time.

Read-out and storage of data from the CCD camera is a slow step in the data acquisition protocol thus, in both laboratory and field work, the number of ringdown events averaged on-chip is adjusted to maximise the signal levels within the dynamic range of the detector. The number of on-chip averages can also be increased during a sequence of measurements to offset any reduction in the laser output. For field 


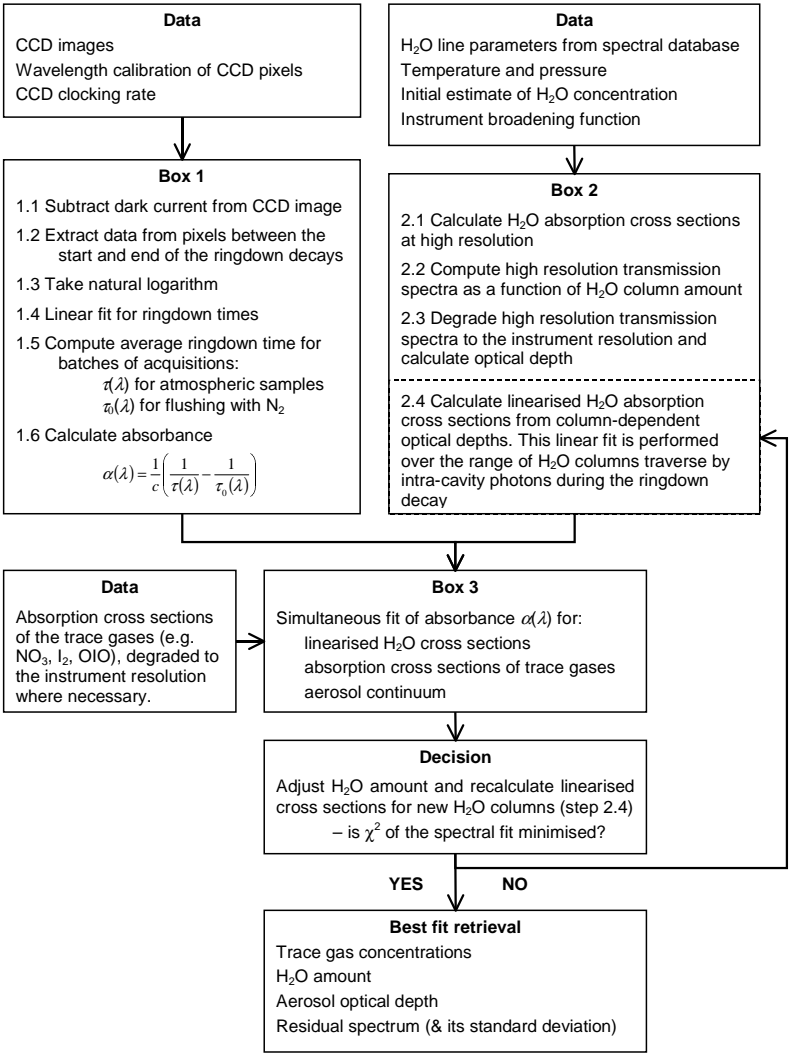

Fig. 9. Flow chart illustrating the logic of the analysis procedure.

studies, scattering/absorption by ambient aerosol is typically the dominant loss of photons circulating within the cavity, greater than even the mirror losses for the highly efficient optics employed here. Thus the clocking rate was adjusted according to the amount of aerosol extinction to ensure that the ringdown decay was dispersed over the full extent of the CCD image section. Having been acquired under laboratory conditions, the ringdown trace for the sample shown in Fig. 8 is essentially free from aerosol losses and so a relatively slow clocking rate of $3.0 \mu$ s per row was used. The clocking rate is also needed to translate pixel number into time, as in the lower panel of Fig. 8.

Weighted linear fits to the natural logarithm of the ringdown signal are shown for the nitrogen flush and the sample $\left(\mathrm{H}_{2} \mathrm{O}\right.$ and $\left.\mathrm{N}_{2}\right)$ decays in the lower panel of Fig. 8. The fits are weighted according to the absolute signal levels and, as indicated in the figure, are applied to the decaying signal between its maximum and the end of the clocking sequence. In practice however, the fitted region was restricted to fewer pixels on occasions where the ringdown signal had decayed to levels close to the dark current before reaching the accumulation region. The linear fit to the nitrogen flush data yields a ringdown time $\tau_{0}(\lambda)$ with an uncertainty typically less than $1 \%$. However the data for the humidified nitrogen sample exhibits the pronounced curvature characteristic of a multi- exponential decay (Zalicki and Zare, 1995; Ball and Jones, 2003). Although the time constant $\tau(\lambda)$ extracted from a linear fit of the sample data underestimates the decay rate on resonance with the water line, with care it can nevertheless be used to determine the absorbance of the sample (Sect. 4).

The effect of narrowband absorbers on cavity ringdown measurements made with spectrally broad radiation has been discussed in depth (Zalicki and Zare, 1995; Ball and Jones, 2003), and references therein. In particular, a method involving linearized absorption cross sections has successfully been applied to extract quantitative amounts of oxygen from BBCRDS spectra, and this method is applied here to fit the water vapour structure in BBCRDS spectra acquired during the NAMBLEX campaign. The reason for the multiexponential decay in the sample data of Fig. 8 is that the resolution of the BBCRDS instrument $\left(0.1 \mathrm{~nm}\right.$ or approx. $2 \mathrm{~cm}^{-1}$ FWHM at $660 \mathrm{~nm}$ ) is insufficient to resolve the strong and highly structured absorption features due to ambient water vapour. The full widths at half maximum of water vapour's ro-vibrational transitions are of the order of $0.2 \mathrm{~cm}^{-1}$ in the $4 v+\delta$ and $5 v$ polyads which, respectively, overlap the much broader electronic transitions of $\mathrm{NO}_{3}$ around $660 \mathrm{~nm}$ and OIO and $\mathrm{I}_{2}$ around $570 \mathrm{~nm}$. Fig. 4 above shows the cross section of water vapour from a line-by-line calculation using parameters listed in the Brussels-Reims (BR) spectral database, (Coheur et al., 2002), (Fally et al., 2003). Variations in the mirror reflectivity, though highly significant over the wavelength range of the BBCRDS spectrometer, are not important over the limited range of wavelengths imaged onto an individual CCD pixel.

\section{Analysis}

\subsection{Overview}

The logic of the analysis procedure is summarized by the flow chart in Fig. 9. The top half of the flow chart shows two parallel calculations: absorbance spectra are calculated from the CCD images on the left hand side (Box 1) whilst linearized absorption cross sections are calculated for an initial estimate of the water amount on the right hand side (Box 2). The two streams unite in Box 3 where the linearized water cross sections and the absorption cross sections of the trace gases are fitted simultaneously to the absorption spectra. A decision box follows whose outcome depends on whether the $\chi^{2}$ value of the spectral fit has reached its minimum. If $\chi^{2}$ has not been minimised, the water vapour amount is adjusted, the linearized cross sections recalculated for the new water amount and spectral fitting performed again. The best fit (minimum $\chi^{2}$ ) yields the following parameters and their error margins: the concentrations of one or more trace gases, the $\mathrm{H}_{2} \mathrm{O}$ amount, an average aerosol optical extinction over the spectrometer's bandwidth and the residual spectrum. The 
following sections explain the different computation stages in greater detail.

\subsection{Calculation of the absorption spectrum from CCD im- ages (Box 1)}

The first step in calculating an absorption spectrum is to ascribe a wavelength to each of the 512 pixels along the wavelength dispersed axis of the CCD camera. This task was performed once for each day's data by comparing the differential structure in a representative CCD image with the wavelengths of identifiable absorption lines due to water vapour. The wavelength scale was produced from a polynomial fit to the pixel number versus the wavelength of between 10 and 20 absorption lines. Occasionally within a long sequence of measurements, slight shifts were observed in the position of the water structure in the CCD images, and these were corrected in the analysis software by shifting the wavelength scale in multiples of $1 / 10$ of a pixel.

The CCD images were manipulated in an analogous manner to that discussed above for the two wavelength resolved ringdown decays shown in Fig. 8. First, the appropriate dark currents were subtracted from the CCD images. Then the pixels defining the beginning and the end of the ringdown decay were identified. For measurements in the $660 \mathrm{~nm}$ region, the ringdown decays typically spanned 100 pixels down the clocked axis of the CCD for a clocking rate of $1,1.5$ or $2 \mu \mathrm{s}$ per pixel depending on the amount of aerosol extinction. The CCD images in the region around $570 \mathrm{~nm}$ were acquired at similar clocking rates but, owing to the limited bandwidth of the laser in this spectral region, ringdown decays at the sides of the CCD image often extend fewer (e.g. 60) clocking steps before their intensity became comparable with the dark current. As for the example shown in Fig. 8, the ringdown times were calculated from weighted linear fits to the natural logarithm of the decaying intensity (steps 1.3 to 1.5 ). The absorbance spectrum $\alpha\left(\lambda_{j}\right)$ was calculated using the ringdown times averaged over batches of typically ten sample (and ten flush) CCD images.

\subsection{Calculation of the linearized cross sections (Box 2)}

For the highly efficient mirrors used in the present BBCRDS instrument, light circulating within the cavity probes the absorbers over a wide range of path lengths. Specifically, the absorption bands of water vapour at visible wavelengths are sufficiently strong that absorption by the molecule at line centre is often saturated by the end of the ringdown decay. As noted in Sect. 3, the resolution of the spectrometer is insufficient to fully resolve water vapour's absorption bands and this, coupled with the bands' large optical depths, leads to multi-exponential behaviour in the ringdown decays (e.g. Fig. 8). In the present analysis scheme, multi-exponential decays are treated quantitatively through the calculation and spectral fitting of linearized absorption cross sections for wa-
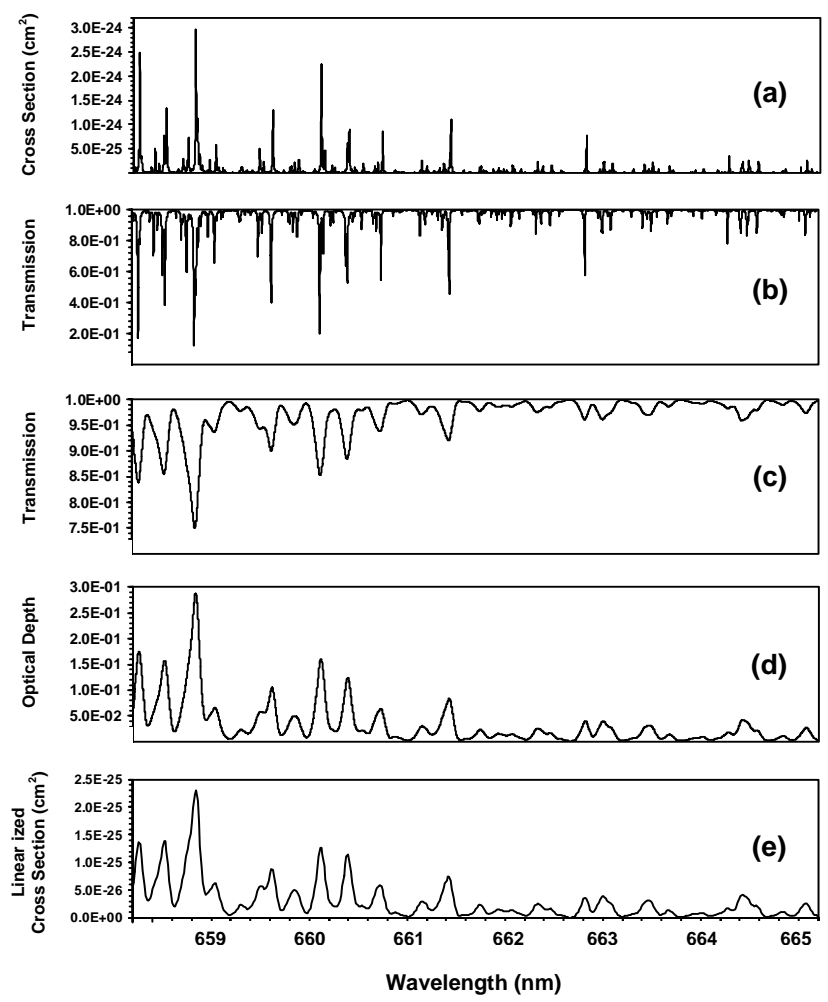

Fig. 10. An illustration of the various stages in the calculation of linearized absorption cross sections in Box 2 of Fig. 9. This example assumes $95 \%$ relative humidity at a temperature of $20^{\circ} \mathrm{C}$ and $1 \mathrm{Atm}$ pressure. (a) High resolution absorption cross sections calculated from the Brussels-Reims database. (b) High resolution transmission spectrum through a water column of $9.7 \times 10^{23}$ molecules $\mathrm{cm}^{-2}$. Typically 300 such transmission spectra were calculated for water columns spanning the full range of $\mathrm{H}_{2} \mathrm{O}$ molecules encountered by intra cavity photons during the ringdown decay. This example corresponds to the water column for the 50th clocking step in a ringdown trace recorded at $1 \mu$ s per pixel clocking rate. (c) The transmission spectrum from panel (b) degraded to the instrument resolution. (d) The optical depth for the transmission spectrum immediately above. (e) The linearized absorption cross sections obtained from a fit of the optical depth versus water column for a ringdown trace of 100 clocking steps, see also Fig. 11.

ter vapour. The cross sections of the other absorbers are either spectrally broad compared to the instrument function $\left(\mathrm{NO}_{3}\right.$, OIO and aerosol) or their optical depth in ambient samples is small $\left(\mathrm{I}_{2}\right)$, neither of which leads to significant multi-exponential behaviour in ringdown decays (Zalicki and Zare, 1995; Newman et al., 1999; Ball and Jones, 2003). Consequently absorption cross sections of $\mathrm{NO}_{3}$ etc. at the resolution of the BBCRDS instrument were calculated by simply degrading the literature cross section to the resolution of the instrument.

Calculation of water's linearized absorption cross sections begins with a line-by-line calculation of the molecule's 


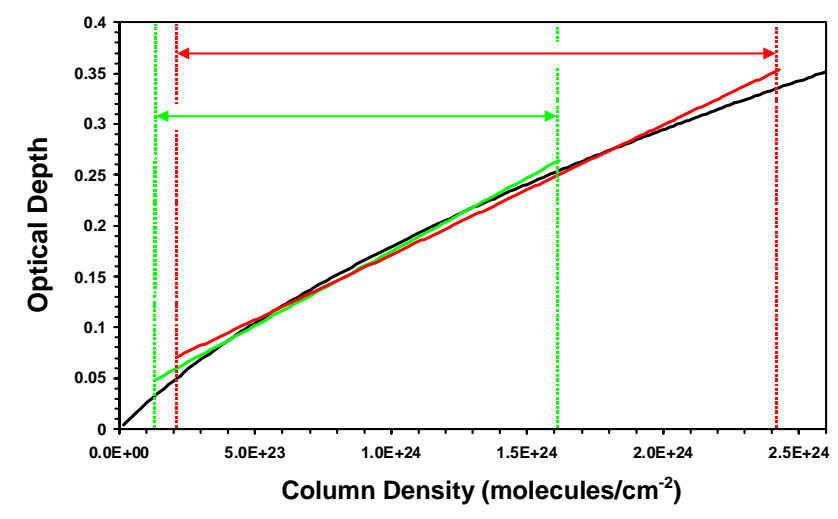

Fig. 11. The non-linear variation in the optical depth with water column amount at the resolution of the BBCRDS instrument. These data are for a single wavelength on resonance with a water absorption line. The green and red lines illustrate examples of fits to retrieve the linearized absorption cross sections for ringdown decays sampling different ranges of water columns, either due to an increase in ambient $\left[\mathrm{H}_{2} \mathrm{O}\right]$ or to the use of a slower CCD clocking rate $($ green $\rightarrow$ red $)$.

absorption cross sections at high spectral resolution using, in this case, the Brussels-Reims (BR) spectral database of Coheur et al. (2002), (Coheur et al., 2002; Fally et al., 2003). Laboratory studies (Bitter, 2004) have shown that the BR database provides a better parameterisation of water's differential structure in BBCRDS spectra around $660 \mathrm{~nm}$ than either the HITRAN2000 (Rothman et al., 2003) or the ESA data sets (Schermaul et al., 2001), and thus is preferred in this work. At room temperature, the amount of spurious $\mathrm{NO}_{3}$ retrieved from fitting the differential structure in laboratory BBCRDS spectra of humidified nitrogen was below the detection limit of the current spectrometer, indicating that any inadequacies in the BR database's parameterisation of water's spectroscopy do not affect the retrieval of $\mathrm{NO}_{3}$ concentrations. However larger amounts of $\mathrm{NO}_{3}$ were retrieved from fitting spectra of humidified nitrogen at $60^{\circ} \mathrm{C}$, the temperature used to thermally dissociate $\mathrm{N}_{2} \mathrm{O}_{5}$ to $\mathrm{NO}_{3}$. Again, the BR database yielded a better fit than either the HITRAN2000 or ESA databases, though the amount of spurious $\mathrm{NO}_{3}$ (around 1 pptv) was significant at this elevated temperature. Consequently an appropriate correction has been applied to measurements of $\mathrm{NO}_{3}+\mathrm{N}_{2} \mathrm{O}_{5}$.

High resolution water absorption cross sections calculated using the BR database have be shown previously in Fig. 4. They are reproduced over a shorter spectral region in Fig. 10 to illustrate pictorially the results of the calculations in Box 2 of the flowchart in Fig. 9. The high resolution absorption cross sections are used to calculate high resolution transmission spectra over the range of optical depths encountered by the photons circulating inside the ringdown cavity (step 2.2). A transmission spectrum is calculated for the water column $\left(=t_{k} \times n_{0} \times c\right)$ at each time step in the CCD clocking sequence $t_{k}$. Here $n_{0}$ is an initial estimate of the water vapour concentration obtained from a commercial solid state humidity meter and $c$ is the speed of light. In practice the running integer $k=1,2,3, \ldots$ extends beyond the final clocking step of the ringdown decay to allow for possible increases in the water vapour concentration during a run of measurements. An example of a high resolution transmission spectrum is shown in panel (b) of Fig. 10 for one of the clocking steps approximately half way through the ringdown decay in Fig. 8. Note that the stronger absorption lines are already close to saturation.

The next step of the calculation convolves the high resolution transmission spectra with the instrument function to yield transmission spectra degraded to the resolution of the BBCRDS spectrometer (step 2.3 in Box 2 of Fig. 9 and panel (c) of Fig. 10). The instrument function is obtained from a CCD image of a monochromatic source (HeNe laser or an atomic emission lamp) or a broadband source sampled through the spectrometer with the grating set to zero order. To reduce the computational effort, the low resolution transmission spectra are now reduced to 512 data points, one at the central wavelength of each pixel of the CCD image. An optical depth spectrum at the resolution of the spectrometer is then calculated from each column dependent transmission spectrum, see panel (d) of Fig. 10. The optical depth at the resolution of the BBCRDS instrument is not a linear function of the column density for wavelengths on resonance with a water absorption line, a point further illustrated in Fig. 11. Indeed the curvature exhibited in Fig. 11 and the curvature of the multi-exponential decay in the lower panel of Fig. 8 are both manifestations of the limited spectral resolution of the BBCRDS instrument. But importantly the former can be used to correct for the latter through the use of linearized absorption cross sections.

Figure 11 illustrates how linearized absorption cross sections are calculated from a linear fit of the optical depths versus the water column (step 2.4 of Box 2 in Fig. 9). As anticipated above, the value of the linearized cross section depends on the range of column densities included in the linear fit. Thus a fit conducted over a larger range column densities necessarily yields a smaller linearized cross section: for example, compare the gradients of the green and red lines in Fig. 11. The linearized absorption cross sections shown panel (e) of Fig. 10 therefore have a subtly different spectral structure to the optical depth spectrum shown in panel (d) above. For the analysis of BBCRDS spectra, the subset of column densities selected to calculate the linearized cross sections are those sampled by the intra-cavity photons, and are determined by the start and end pixels of the decay traces used to fit the ringdown times. In a further subtlety, the linear fits shown in Fig. 11 do not start at zero column density because, as noted in Sect. 3, the finite width of the CCD mask means that the first pixel at the top of the ringdown decay samples light that has been circulating in the cavity for up to ten clocking steps. 
4.4 The retrieval of species amounts with a simultaneous spectral fit (Box 3)

The concentrations of the various absorbers contributing to the BBCRDS spectra of ambient samples were retrieved by a simultaneous fit of $\alpha\left(\lambda_{j}\right)$ with the absorption cross sections of the trace gas(es) and the linearized cross sections for water vapour (Box 3 of Fig. 9). Depending on the spectral bandwidth, the fit also included a linear or quadratic function to account for the unstructured but variable aerosol extinction. In these spectral fits, the amplitudes of the cross sections were adjusted as variables in a least-squares method described by Press et al. (2001).

As discussed above, the precision of the retrieval depends crucially on an ability to fit and thus remove the differential structure due to water vapour thereby revealing the small underlying absorption signals due to $\mathrm{NO}_{3}$ etc. (see Fig. 7 for example). Since the concentration of atmospheric water vapour can change significantly during a run of measurements, the analysis procedure allows for the linearized water cross sections to be re-calculated from step 2.4 of Box 2 for a different water amount by fitting the optical depth versus column density over an adjusted range of column amounts. An extreme example of such an adjustment would be the red and green linear fits shown in Fig. 11. The simultaneous spectral fit is then repeated with the revised water cross sections, and the quality of the fit - specifically its $\chi^{2}$ value - is compared to the previous fit (the decision box of Fig. 9). The water concentration is adjusted in this way until the $\chi^{2}$ value of the fit reaches its minimum. Once this has been achieved, the analysis routine outputs the "best fit" parameters and their associated uncertainties, namely the concentrations of the trace gas(es) and water vapour, the average value of the aerosol extinction across the bandwidth of the measurement, and residual spectrum remaining after subtraction of the differential structure and the aerosol continuum from the measured absorption spectrum. The standard deviation of the residual spectrum provides an estimate of the minimum absorbance that could be detected by the instrument. It is thus is a more obvious metric of the quantity of the spectral fitting procedure than the $\chi^{2}$ value (indeed the two were found to be closely correlated), and the former quantity is quoted together with the examples of fitted BBCRDS spectra in the following section and in our companion paper (Bitter et al., 2005 ${ }^{1}$ ).

The calculation of several linearized cross sections of $\mathrm{H}_{2} \mathrm{O}$ in an iterative approach can be computation intensive and is slow for large sets of data such as collected during the NAMBLEX field campaign. Therefore, as long as the variation in water amounts was small throughout a run of measurements, the linearized cross sections calculated for an average water amount were used in the spectral fits without further iterative refinement. Despite being slightly inaccurate, this simpler method still treated the $\mathrm{H}_{2} \mathrm{O}$ cross sections as a linear variable when fitting the absorbance $\alpha\left(\lambda_{j}\right)$. The approach

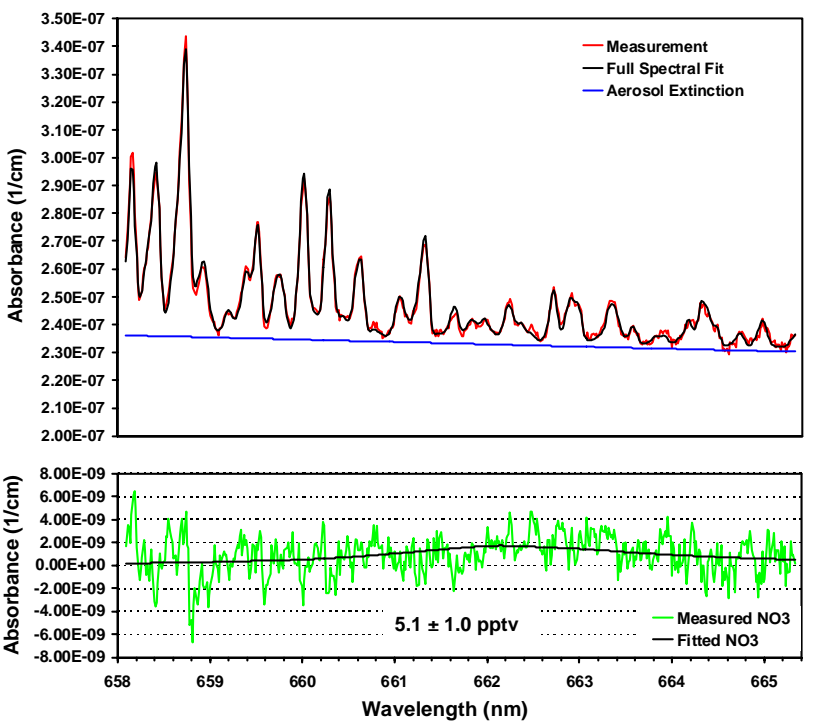

Fig. 12. (Top panel) Measured (red) and fitted (black) absorption spectra and aerosol extinction (blue) in the wavelength region used to detect $\mathrm{NO}_{3}$. The majority of the spectral structure arises from the $4 v+\delta$ bands of ambient water vapour. The measured spectrum comes from the summation of $10 \mathrm{CCD}$ images acquired on ambient samples during NAMBLEX, each CCD image being the on chip integration of 100 ringdown events (total acquisition time $=100 \mathrm{~s}$ ). (Bottom panel) The $\mathrm{NO}_{3}$ absorption signal and its fit: $\left[\mathrm{NO}_{3}\right]=5.1 \pm 1.0 \mathrm{pptv}$. The standard deviation of the residual spectrum was $1.7 \times 10^{-9} \mathrm{~cm}^{-1}$.

is justified because the water amounts obtained are in good agreement with those made by commercial humdity probes (Bitter et al., 2005 ${ }^{1}$ ). Moreover, laboratory experiments conducted on humidified nitrogen have shown that the errors in the retrieved $\mathrm{H}_{2} \mathrm{O}$ amounts introduced by this simplification were below $3 \%$ in all cases for the NAMBLEX data set (Bitter, 2004).

\section{Example spectra}

Representative examples of BBCRDS spectra and their associated spectral fits are shown in Fig. 12 and Fig. 13 for the wavelength regions used to detect $\mathrm{NO}_{3}(662 \mathrm{~nm})$ and $\mathrm{OIO}$ and $\mathrm{I}_{2}(568 \mathrm{~nm})$. The top panel of each figure shows the measured BBCRDS spectrum overlaid by the fitted spectrum. The unstructured continuum due to aerosol extinction is also shown. The lower panel of Fig. 12 shows the differential absorption due to $\mathrm{NO}_{3}$ overlaid by the fitted absorption spectrum of $5.1 \mathrm{pptv}$ of $\mathrm{NO}_{3}$. The uncertainty in the fitted $\mathrm{NO}_{3}$ mixing ratio $( \pm 1 \mathrm{pptv})$ is greater than that for the spectra shown previously in Fig. 7 because a much shorter integration time of $100 \mathrm{~s}$ was typically used during NAMBLEX to monitor more rapid variations in the $\mathrm{NO}_{3}$ radical (Brown et al., 2002a, Bitter et al., 2005 ${ }^{1}$ ) that would have been averaged out over the $42 \mathrm{~min}$ integration time used to acquire the 


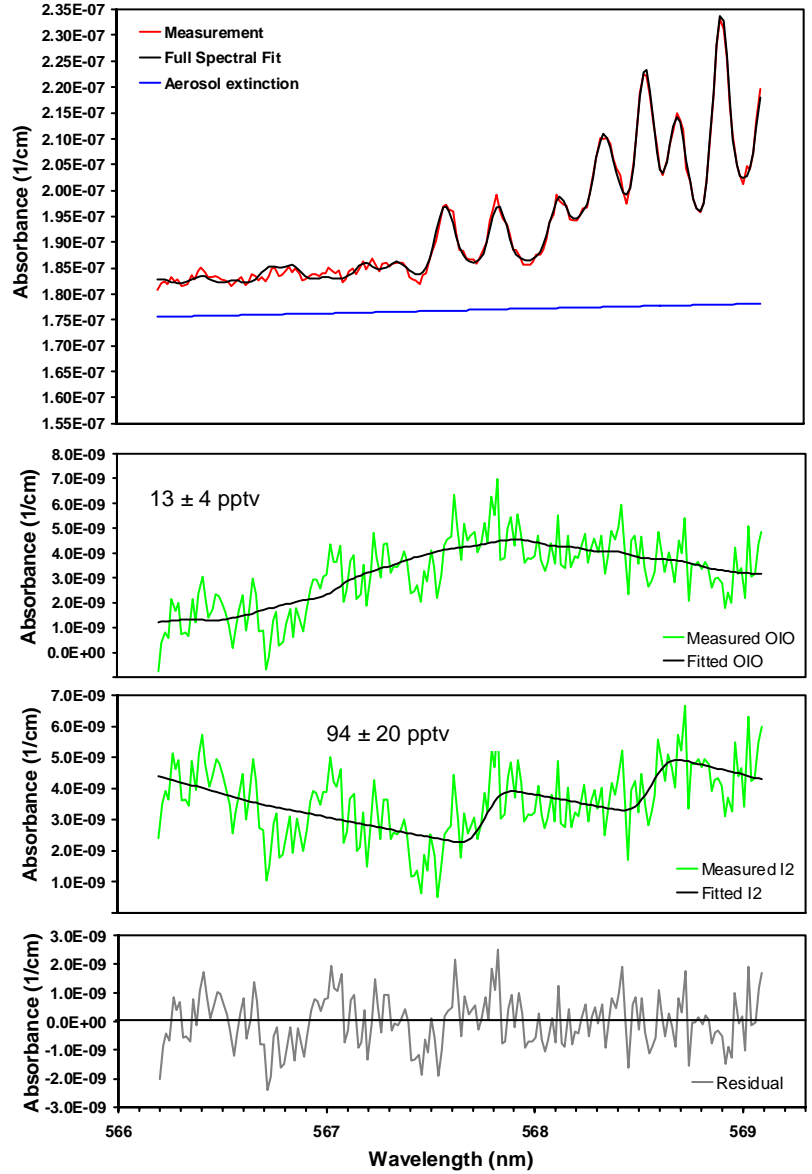

Fig. 13. (Top panel) Measured (red) and fitted (black) absorption spectra and aerosol extinction (blue) in the wavelength region used to detect $\mathrm{OIO}$ and $\mathrm{I}_{2}$. The majority of the spectral structure arises from the $5 v$ bands of ambient water vapour. The measured spectrum comes from the summation of 40 CCD images acquired on ambient samples during NAMBLEX, each CCD image being the on chip integration of 40 ringdown events (total acquisition time $=10 \mathrm{~min}$ ). (Lower panels) The $\mathrm{OIO}$ and $\mathrm{I}_{2}$ absorption signals and their fits: $[\mathrm{OIO}]=13 \pm 4 \mathrm{pptv}$ and $\left[\mathrm{I}_{2}\right]=94 \pm 20 \mathrm{pptv}$. The standard deviation of the residual spectrum shown in the bottom panel is $9.1 \times 10^{-10} \mathrm{~cm}^{-1}$.

data in Fig. 7. Time series for $\mathrm{NO}_{3}$ and $\mathrm{NO}_{3}+\mathrm{N}_{2} \mathrm{O}_{5}$ are presented in Bitter et al. (2005) ${ }^{1}$ where they are compared with $\mathrm{NO}_{3}$ mixing ratios measured over a $4.2 \mathrm{~km}$ path by a long path DOAS instrument also deployed at NAMBLEX (SaizLopez and Plane, 2004; Saiz-Lopez et al., 2005b).

The lower panels of Fig. 13 show the absorption features of $\mathrm{OIO}$ and $\mathrm{I}_{2}$ and the residual spectrum from the spectral fit to the atmospheric absorption spectrum in the top panel. The corresponding $\mathrm{OIO}$ and $\mathrm{I}_{2}$ mixing ratios were $13 \pm 4 \mathrm{pptv}$ and $94 \pm 20$ pptv, respectively, and the integration time was $10 \mathrm{~min}$. Although the mixing ratio of these iodine compounds were below the detection limits of the present instrument for much of NAMBLEX, substantial concentrations were detected around sunset at low tide (i.e. the conditions under which the spectra in Fig. 13 were recorded). Moreover the BBCRDS data are "point" measurements of OIO and $\mathrm{I}_{2}$ whose atmospheric concentrations have hitherto only been quantified as mixing ratios averaged over the extended paths of long-path DOAS observations, for example Saiz-Lopez and Plane (2004) and references therein. Time series for the iodine compounds are presented in Bitter et al. $(2005)^{1}$ and their significance for the gas-to-particle nucleation of aerosol is discussed in Saiz-Lopez et al. (2005a).

\section{Conclusions}

The operating principles, instrumentation and field deployment of a broadband cavity ringdown spectrometer have been described. The instrument is able to make sensitive measurements of the concentrations of short-lived trace gases via their spectrally broad electronic transitions at visible wavelengths. Analysis of the absorption spectra obtained for ambient samples requires the quantitative fitting of the partially saturated absorption bands of water vapour. This has been achieved through the use of linearized absorption cross sections in a numerical routine that allows the trace gas concentrations, the ambient water vapour concentrations and an average optical aerosol extinction to be quantified from a simultaneous fit of the measured spectra using methods adapted from the analysis of long path DOAS spectra.

The spectrometer's first field deployment was during the North Atlantic Marine Boundary Layer Experiment (NAMBLEX) at Mace Head in 2002. Quantitative measurements were made of $\mathrm{NO}_{3}$ and $\mathrm{N}_{2} \mathrm{O}_{5}$ via the former molecule's absorption band at $662 \mathrm{~nm}$, and of OIO and $\mathrm{I}_{2}$ via their overlapping absorption bands around $570 \mathrm{~nm}$. The detection of OIO and $\mathrm{I}_{2}$ adds two more molecules to the growing list of species quantified in the atmosphere by cavity ringdown spectroscopy and related techniques. The measurements are also the first to quantify the localised concentrations of OIO using a "point" measurement technique.

Representative spectra were presented for all atmospheric absorbers detected during the NAMBLEX field campaign. Typical $\mathrm{NO}_{3}$ detection limits were of the order of 1 pptv for BBCRDS spectra integrated for $100 \mathrm{~s}$, and thus the instrument's sensitivity is sufficient to follow the variability of this radical throughout most of the range in its atmospheric lifetimes at night. The detection limits achieved for OIO and $\mathrm{I}_{2}$ are 4 pptv and 20 pptv respectively for an integration time of $10 \mathrm{~min}$. The full time series of the trace gas concentrations, water vapour amounts and aerosol extinction are presented in a companion paper in this issue (Bitter et al., 2005 ${ }^{1}$ ). Here, the focus was mostly on a description of the instrument and the spectral fitting method.

The detection limits achieved for the iodine compounds during NAMBLEX are slightly disappointing given the detection limits demonstrated for $\mathrm{NO}_{3}$ and the longer 
integration times used at $570 \mathrm{~nm}$ (N.B. the standard deviation of the residual spectrum in Fig. 13 is actually smaller than that for Fig. 12). It is unlikely that the lesser sensitivity can be attributed to the poorer reflection efficiency of the $570 \mathrm{~nm}$ mirrors since the largest attenuation of intracavity photons typically comes from the extinction by ambient aerosol which is similar in the two spectral regions. Rather the primary reason seems to be the narrower bandwidth of the dye laser output at shorter wavelengths (see Fig. 3) which reduces the amount of differential structure in the absorption cross sections of the trace gases that can be fitted to the BBCRDS spectra, thereby reducing the precision of the retrieval. Recent attempts to further develop the BBCRDS instrument have therefore focussed on widening the bandwidth of the light source through the purchase of a smaller, air-cooled, laser system operating with a more favourable pyrromethene 580 dye. A new CCD camera also allows the ringdown decay to be imaged over more pixels along its clocked axis. Early laboratory trials of the improved system are encouraging: BBCRDS spectra of $\mathrm{I}_{2}$ at a dilution of around $100 \mathrm{pptv}$ have shown an uncertainty in the retrieved $\left[\mathrm{I}_{2}\right]$ of less than $10 \mathrm{pptv}$ for an integration time of $140 \mathrm{~s}$ and a laser bandwidth of $15 \mathrm{~nm}$ centred at $555 \mathrm{~nm}$. These advances should lead to substantially improved detection limits for the iodine compounds in the field and additionally benefit the $\mathrm{NO}_{3}$ measurements.

Acknowledgements. This work was supported by the Natural Environment Research Council under grants NER/J/S/1999/00131 and NER/B/S/2001/00840. We are also grateful to the organisers of the NAMBLEX campaign and to the staff of the Mace Head Atmospheric Research Station.

Edited by: D. Heard

\section{References}

Ashworth, S. H., Allan, B. J., and Plane, J. M. C.: High resolution spectroscopy of the OIO radical: Implications for the ozonedepleting potential of iodine, Geophys. Res. Lett., 29(10), 14561459, 2002.

Atkinson, D. B.: Solving chemical problems of environmental importance using cavity ring-down spectroscopy, The Analyst, 128, 117-125, 2003.

Baer, D. S., Paul, J. B., Gupta, M., and O'Keefe, A.: Sensitive absorption measurements in the nearinfrared region using off-axis integrated-cavityoutput spectroscopy, Appl. Phys. B, 75, 261265, 2002.

Ball, S. M. and Jones, R. L.: Broad-Band Cavity Ring-Down Spectroscopy, Chem. Rev., 103, 5239-5262, 2003.

Ball, S. M., Povey, I. M., Norton, E. G., and Jones, R. L.: Broadband cavity ringdown spectroscopy of the $\mathrm{NO}_{3}$ radical, Chem. Phys. Lett., 342, 113-120, 2001.

Berden, G., Peeters, R., and Meijer, G.: Cavity ring-Down spectroscopy: Experimental schemes and applications, Int. Rev. Phys. Chem., 19(4), 565-607, 2000
Bitter, M.: Cavity Ring Down Spectroscopy for Atmospheric Applications, Ph.D. thesis, University of Cambridge, United Kingdom, 2004.

Brown, S. S.: Absorption Spectroscopy in High-Finesse Cavities for Atmospheric Studies, Chem. Rev., 103, 5219-5238, 2003.

Brown, S. S., Stark, H., Ciciora, S. J., McLaughlin, R. J., , and Ravishankara, A. R.: Simultaneous in situ detection of atmospheric $\mathrm{NO}_{3}$ and $\mathrm{N}_{2} \mathrm{O}_{5}$ via cavity ring-down spectroscopy, Rev. Sci. Inst., 73(9), 3291-3301, 2002a.

Brown, S. S., Stark, H., and Ravishankara, A. R.: Cavity ring-down spectroscopy for atmospheric trace gas detection: application to the nitrate radical $\left(\mathrm{NO}_{3}\right)$, Appl. Phys. B Lasers and Optics, 75, 175-182, 2002b.

Coheur, P.-F., Fally, S., Carleer, M., Clerbaux, C., Colin, R., Jenouvrier, A., Mérienne, M.-F., Hermans, C., and Vandaele, A. C.: New water vapor line parameters in the $26000-13000 \mathrm{~cm}^{-1}$ region, J. Quant. Spec. Rad. Transf., 74, 493-510, 2002.

Fally, S., Coheur, P.-F., Carleer, M., Clerbaux, C., Colin, R., Jenouvrier, A., Mérienne, M.-F., Hermans, C., and Vandaele, A. C.: Water vapor line broadening and shifting by air in the 26000 $13000 \mathrm{~cm}^{-1}$ region, J. Quant. Spec. Rad. Transf., 82, 119-131, 2003.

Fawcett, B. L., Parkes, A. M., Shallcross, D. E., and Orr-Ewing, A. J.: Trace detection of methane using continuous wave cavity ring-down spectroscopy at $1.65 \mu \mathrm{m}$, Phys. Chem. Chem. Phys., 4, 5960-5965, 2002.

Himmelmann, S., Orphal, J., Bovensmann, H., Richter, A., Ladstatter-Weissenmayer, A., and Burrows, J. P.: First observation of the $\mathrm{OIO}$ molecule by time-resolved flash photolysis absorption spectroscopy, Chem. Phys. Lett., 251(5), 330-334, 1996.

Jongma, R. T., Boogaarts, M. G. H., Holleman, I., and Meijer, G.: Trace gas detection with cavity ring down spectroscopy, Rev. Sci. Inst., 66(4), 2821-2828, 1995.

Menzel, L., Kosterev, A. A., Curl, R. F., Tittel, F. K., Gmachl, C., Capasso, F., Sivco, D. L., Baillargeon, J. N., Hutchinson, A. L., Cho, A. Y., and Urban, W.: Spectroscopic detection of biological NO with a quantum cascade laser, Appl. Phys. B, 72, 859-863, 2001.

Newman, S. M., Lane, I. C., Orr-Ewing, A. J., Newnham, D. A., and Ballard, J.: Integrated absorption intensity and Einstein coefficients for the $\mathrm{O}_{2} \mathrm{a}^{1} \Delta_{g}-\mathrm{X}^{3} \Sigma_{g}^{-}(0,0)$ transition: A comparison of cavity ringdown and high resolution Fourier transform spectroscopy with a long-path absorption cell, J. Chem. Phys., 110(22), 10749-10757, 1999.

Nicolet, M.: On the molecular scattering in the terrestrial atmosphere: An empirical formula for its calculation in the homosphere, Planet. Space Sci., 32(11), 1467-1468, 1984.

Plane, J. M. C. and Smith, N.: Atmospheric Monitoring By Differential Optical Absorption Spectroscopy, Chapter 5, in: Spectroscopy in Environmental Science, Advances in Spectroscopy, Volume 24, John Wiley and Sons Inc., 1995.

Platt, U.: Modern methods of the measurement of atmospheric trace gases, Invited Lecture, Phys. Chem. Chem. Phys., 1, 5409-5415, 1999.

Povey, I. M., South, A. M., t'Kint de Roodenbeke, A., Hill, C., Freshwater, R. A., and Jones, R. L.: A broadband lidar for the measurement of tropospheric constituent profiles from the ground, J. Geophys. Res., 103(D3), 3369-3380, 1998. 
Press, W. H., Teukolsky, S. A., Vetterling, W. T., and Flannery, B. P.: Numerical Recipes in Fortran 77, Second Edition, The Art of Scientific Computing, Cambridge University Press, 2001.

Rothman, L. S., Barbe, A., Benner, D. C., Brown, L., CamyPeyret, C., Carleer, M. R., Chance, K., Clerbaux, C., Dana, V., Devi, V. M., Fayt, A., Flaud, J.-M., Gamache, R., Goldman, A., Jacquemart, D., Jucks, K., Lafferty, W., Mandin, J.-Y., Massie, S. T., Nemtchinov, V., Newnham, D. A., Perrin, A., Rinsland, C., Schroeder, J., Smith, K. M., Smith, M. A. H., Tang, K., Toth, R. A., Auwera, J. V., Varanasi, P., and Yoshino, K.: The HITRAN molecular spectroscopic database: edition of 2000 including updates through 2001, J. Quant. Spec. Rad. Transf., 82, 5-44, 2003.

Saiz-Lopez, A. and Plane, J. M. C.: Novel iodine chemistry in the marine boundary layer, Geophys. Res. Lett., 31(4), L04 112, 2004.

Saiz-Lopez, A., Saunders, R. W., Joseph, D. M., Ashworth, S. H., and Plane, J. M. C.: Absolute absorption cross-section and photolysis rate of $\mathrm{I}_{2}$, Atmos. Chem. Phys., 4, 1443-1450, 2004, SRef-ID: 1680-7324/acp/2004-4-1443.

Saiz-Lopez, A., Plane, J. M. C., McFiggans, G., Ball, S. M., Bitter, M., Jones, R. L., Hongwei, C., and Hoffmann, T.: Molecular iodine emissions in coastal marine environments: the link to new particle formation, Atmos. Chem. Phys. Discuss., 5, 5405-5439, 2005a,

SRef-ID: 1680-7375/acpd/2005-5-5405.

Saiz-Lopez, A., Shillito, J. A., Coe, H., and Plane, J. M. C.: Measurements and modelling of $\mathrm{I}_{2}, \mathrm{IO}, \mathrm{OIO}, \mathrm{BrO}$ and $\mathrm{NO}_{3}$ in the mid-latitude marine boundary layer, Atmos. Chem. Phys. Discuss., in press, $2005 \mathrm{~b}$.
Schermaul, R., Learner, R. C., Newnham, D. A., Ballard, J., Zobov, N. F., Belmiloud, D., and Tennyson, J.: The Water Vapor Spectrum in the Region $8600-15000 \mathrm{~cm}^{-1}$ : Experimental and Theoretical Studies for a New Spectral Line Database, I. Laboratory Measurements, J. Mol. Spec., 208, 32-42, 2001.

Simpson, W. R.: Continuous wave cavity ring-down spectroscopy applied to in situ detection of dinitrogen pentoxide $\left(\mathrm{N}_{2} \mathrm{O}_{5}\right)$, Rev. Sci. Inst., 74(7), 3442-3452, 2003.

Smith, J. D. and Atkinson, D. B.: A portable pulsed cavity ringdown transmissometer for measurement of the optical extinction of the atmospheric aerosol, The Analyst, 126, 1216-1220, 2001.

Wängberg, I., Etzkorn, T., Barnes, I., Platt, U., and Becker, K. H.: Absolute Determination of the Temperature Behaviour of the $\mathrm{NO}_{2}+\mathrm{NO}_{3}+(\mathrm{M}) \leftrightarrow \mathrm{N}_{2} \mathrm{O}_{5}+(\mathrm{M})$ Equilibrium, J. Phys. Chem. A, 101, 9694-9698, 1997.

Wayne, R. P., Barnes, I., Biggs, P., Burrows, J. P., Canosa-Mas, C. E., Hjorth, J., LeBras, G., Moortgat, G. K., Perner, D., Poulet, G., Restelli, G., and Sidebottom, H.: The nitrate radical: Physics, chemistry and the atmosphere, Atmos. Environ. A, 25, 1-203, 1991.

Wheeler, M. D., Newman, S. M., Orr-Ewing, A. J., and Ashfold, M. N. R.: Cavity ring-down spectroscopy, J. Chem. Soc., Faraday T rans., 94(3), 337-351, 1998.

Yokelson, R. J., Burkholder, J. B., Fox, R. W., Talukdar, R. K., and Ravishankara, A. R.: Temperature Dependence of the $\mathrm{NO}_{3}$ Absorption Spectrum, J. Phys. Chem., 98, 13 144, 1994.

Zalicki, P. and Zare, R. N.: Cavity ring-down spectroscopy for quantitative absorption measurements, J. Chem. Phys., 102(7), 2708-2717, 1995. 